Gut, 1985, 26, 1210-1213

\title{
DR and non-DR Ia allotypes are associated with susceptibility to coeliac disease
}

\author{
G R CORAZZA, P TABACCHI, M FRISONI, C PRATI, AND G GASBARRINI \\ From the III Departiment of Medical Pathology, S Orsola University Hospital, and the General Laboratory, \\ Malpighi Hospital, Bologna, Italy
}

SUMMARY We have studied the frequency of HLA-DR, -MT, and -MB antigens in adult patients with coeliac disease and in a group of healthy controls, evaluating the strength of the observed associations by measuring the aetiologic fractions. Among the antigens significantly associated with coeliac disease, MB2 (DQw2) showed an aetiologic fraction higher than those of DR3 and DR7. Our results suggest that MB2, as associated more frequently than other specificities with a hypothetical disease predisposing gene, may play a role in the pathogenesis of coeliac disease. The significant association of DR3 and DR7 with coeliac disease may be ascribed to linkage disequilibrium of these antigens with MB2.

A number of immunologic diseases have been reported in association with HLA-DR antigens which are regarded as human homologues of murine Ia antigens. ${ }^{P}$ Recently increasing evidence has suggested that two additional series of Ia genes code for two additional series of Ia antigens termed $\mathrm{MB}^{2}$ and MT. ${ }^{3}$ Little is known about the association of these newly defined antigens and disease, but MB1 and MT2 have been reported associated with systemic lupus erythematosus ${ }^{4}$ and primary sicca syndrome. ${ }^{5}$ Moreover, it is noteworthy that the association between MB1 and systemic lupus erythematosus ${ }^{4}$ and between MT2 and primary sicca syndrome $e^{5}$ has been shown to be stronger than those between DR antigens and the above mentioned conditions.

These clinical studies suggest that MB and MT antigens may be more important than DR in genetic predisposition to some diseases. In view of this we have studied the frequency of MB and MT antigens in coeliac disease, a condition known to be associated with DR alleles DR3 and DR7. ${ }^{6}$

\section{Methods}

PATIENTS

Fifty one biopsy proven coeliac patients (aged 15-68 years, mean 38.7 years) were typed for DR and MT antigens. The control group was made up of 56

Address for correspondence: Dr G R Corazza, III Patologia Medica. Policlinico S. Orsola, Via Massarenti 9, 40138 Bologna, Italy.

Received for publication 3 December 1984 unrelated healthy subjects matched for sex, age, ethnic background, and geographic origin with coeliacs.

As far as MB2 and MB3 antigens are concerned, typing was carried out in 34 consecutive unselected and unrelated patients of the above mentioned 45 coeliacs and in 49 out of 56 control subjects.

HLA TYPING

Purified lymphocyte preparations were obtained from heparinised peripheral blood by FicollHypaque sedimentation. Immunoglobulin bearing (B) lymphocytes were isolated from neuraminidase rosette forming cells ( $\mathrm{T}$ lymphocytes) as described by Longo and Ferrara. ${ }^{7}$ Cytotoxicity tests were carried out by standard microcytotoxicity assay for B cells. ${ }^{8}$

$\mathrm{DR}, \mathrm{MT}$ and $\mathrm{MB}$ antigens were defined using a panel of 119 antisera; at least three to four antisera were tested to define each antigen specificity. Fifty four antisera were provided by the UCLA Tissue Typing Laboratory (University of California, Los Angeles, Ca), nine antisera were donated by Dr G B Ferrara (Istituto Tumori, Genova, Italy) and the remaining were some of the alloantisera utilised for disease studies in the 8th Histocompatibility Workshop 1980.

\section{STATISTICAL ANALYSIS}

The statistical significance of differences in the frequency of HLA antigens between coeliac patients and controls was calculated by $\chi^{2}$ analysis with 
Yates' correction. p Values were corrected by the number of comparisons made.

The strength of association between HLA antigens and coeliac disease was estimated for each specificity by the relative risk calculated by the method of Woolf ${ }^{9}$, aetiologic ${ }^{10}$ and preventive ${ }^{11}$ fractions. Aetiologic fraction estimates which of many antigens associated with the same disease has the strongest genetic association with an assumed disease allele and shows how much of a disease is caused by the disease associated factor. The aetiologic fraction ranges from 0 , if there is no association between the disease and the antigen, to 1 when the positive association is maximal - that is, all individuals affected by the disease carry the antigen. Preventive fraction is the analogous of aetiologic fraction when an association is negative.

\section{Results}

The distribution of HLA-DR, -MT and -MB specificities in coeliac patients and controls is shown in the Table. Positive significant associations were found for DR3, DR7 and MB2. The frequency of DR3 was $68.6 \%$ among patients as compared with a control frequency of $25 \%(\mathrm{p}<0.0002)$, giving a relative risk of 6.56 . The frequency of DR7 was $64.7 \%$ among coeliac patients as compared with a control frequency of $23.2 \%(\mathrm{p}<0.0005)$, giving a relative risk of 6.06. The high frequency of the antigen MT2 not only among coeliac patients $(92.1 \%)$ but also in the healthy population $(78.5 \%)$ was responsible for the lack of significant association with coeliac disease.

Of the 34 coeliac patients and 49 controls typed with antisera recognising MB2 and MB3 antigens, 6 and 17 , respectively, were found negative for both antigens. MB2 antigen was found in $76.4 \%$ of 34 patients against $24.4 \%$ of 49 controls $(\mathrm{p}<0.0002)$, giving a relative risk of 10.02 .

The observed frequency distribution has been also evaluated as aetiologic and preventive fraction.

For MB2 antigen the aetiologic fraction $(0 \cdot 69)$ was shown to be higher than those for MT2 $(0 \cdot 63)$, DR3 $(0.58)$ and DR7 $(0.54)$ antigens.

Among negative associations, preventive fraction was particularly high for MT1 $(0 \cdot 26)$, DR5 $(0 \cdot 23)$, MB3 $(0 \cdot 20)$ and DR1 $(0 \cdot 18)$ antigens.

\section{Discussion}

Our results confirm, in adult patients, a significant association of coeliac disease with HLA-DR3 and DR7. As far as the association of the disease with Dw $3^{\text {i2 }}$ and DR $3^{13}$ is concerned, it has been confirmed by all subsequent studies, whereas contrasting results have appeared so far on the association between coeliac disease and DR7. The latter antigen does not seem to be associated with coeliac disease in North America, ${ }^{14}$ Ireland $^{15}$ and the Netherlands, ${ }^{16}$ while in countries such as southern Germany, ${ }^{17}$ France, ${ }^{18}$ Italy, ${ }^{19}$ Spain, ${ }^{20}$ and Israel, ${ }^{21}$ where the association with DR3, though significant, has been shown to be weaker the frequency of DR7 appears significantly increased. All reports but on $^{18}$ on the significant association between DR7 and coeliac disease concern paediatric patients and a recent work from England reports on the association of DR7 with coeliac disease in children but not in adults. ${ }^{22}$ These observations may suggest that juvenile coeliac patients are genetically different from adult coeliac patients. Our results are, however, not in keeping with this view. In fact our study confirms, for DR7, previous observations in childhood coeliac disease $^{17}{ }^{19-21}$ and also the results reported by

Table , Frequency of $D R$ and MT antigens in 51 patients with coeliac disease and in 56 controls. MB typing was performed in 34 patients and 49 controls

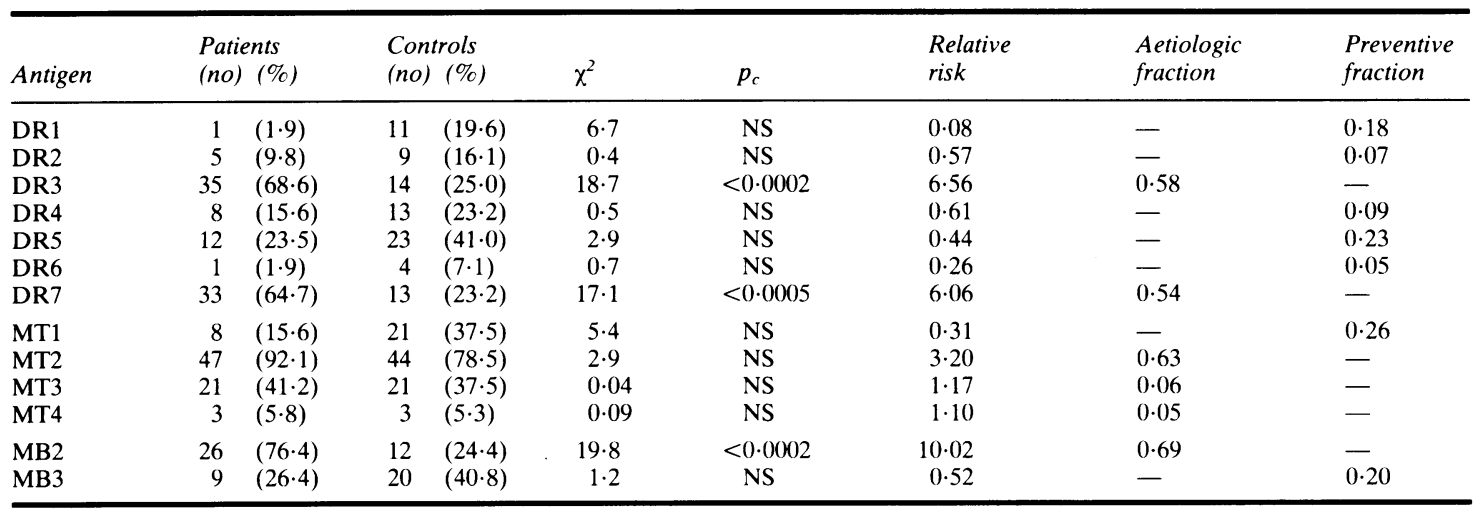


Betuel et $a l^{18}$ in adult patients, suggesting that, at least in southern Europe, no difference seems to exist between HLA status of children and adults with coeliac disease; the genetic heterogeneity of coeliac disease, then, appears to be more a result of different geographic origin than of patients' age.

As far as the frequency in coeliac disease of non-DR Ia allotypes is concerned, we have observed for the first time a significant association with the antigen MB2, which shows a relative risk higher than that of the other specificities significantly associated with coeliac disease - that is, DR3 and DR7. It has been suggested, however, that when several antigens with different allele frequencies are associated with the same disease, it is not possible to estimate which of them is more strongly associated with the disease itself solely by means of relative risk; that depends directly on the frequency of the antigen allele. ${ }^{10} \mathrm{~A}$ more accurate estimate of the strength of an association has been made by the calculation of the so-called aetiologic fraction that detects among the different antigens associated with a certain disease, which antigen has the stronger genetic association with a hypothetical disease allele. ${ }^{10}$ Our results point to MB2 as such an antigen for coeliac disease, as its aetiologic fraction is higher than that observed for DR3 and DR7. MT2 was more common not only among coeliac patients but also among controls. This is not surprising as MT2 is at present considered a broad supertypic antigen including DR3, DR5, DRw6, and DRw8 specificities, controlled by the DR subregion. ${ }^{23}$ That is why the raised aetiologic fraction of MT2 cannot be taken as evidence of a strong association of this antigen and coeliac disease.

In the normal population, MB2 is in strong linkage disequilibrium with DR3 and DR7, ${ }^{24}$ and this supports our view that the significant association of coeliac disease with these latter antigens may be secondary to the association with MB2. This is in keeping with the observation that some DR-associated diseases such as lupus erythematosus, ${ }^{4}$ ocular hystoplasmosis ${ }^{24}$ and Takayasu's arteritis, ${ }^{25}$ have stronger genetic associations with MB antigens.

Our study is in accordance with a recent paper by Tosi et al, ${ }^{26}$ who reported a complete association between coeliac disease and the new specificity DC3, considered the equivalent at the molecular level of MB2. ${ }^{27}$ We have found, however, a lower proportion of MB2 positive coeliac patients $(76.4 \%)$ and this may be because of population differences and/or to minor dissimilarities between DC3 and MB2 and/or to the different techniques used: conventional cytotoxicity assay being used in our study, and RIA typing in that of Tosi et al. ${ }^{26}$

As far as the antigens with a raised preventive fraction for coeliac disease are concerned, apart from MT1 and MB3 which have been considered for the first time in this study, we have confirmed the lower frequency, compared with the healthy population, of DR $1^{19} 2128$ and DR5. ${ }^{21}$ It seems unlikely, however, that these specificities may play a true protective role for the development of coeliac disease. The concept of 'protective gene' would gain strength if a single gene was negatively associated with the disease, but the observation that more genes are less frequent in coeliac patients than in healthy subjects favours the hypothesis of an epiphenomenon compensatory to the increased frequency of DR3, DR7, MT2 and MB2.

In conclusion, our study supports the hypothesis previously formulated by others ${ }^{24} 28$ that MB2, as in linkage disequilibrium with either DR3 and DR7, is the antigen more strongly associated with coeliac disease. Because the association is not absolute, however, MB2 cannot be considered as the direct causative agent of the condition. More likely MB2 is closely associated with a still undefined HLA allele which, together with non-HLA linked genes ${ }^{14} 29$ and environmental factors, plays an important role in promoting the onset of coeliac disease.

This work was presented in part at the National Meeting of the Italian Society of Gastroenterology, Catania, Italy, November 1984. We are indebted to Marinella Cenci for invaluable technical assistance.

\section{Addendum}

After the completion of this study the nomenclature and tassonomy of some HLA specificities have been revised by the 9th International Histocompatability Testing Workshop (Munich, 1984). MB2 is now termed DQw2 and is viewed as a DQ subregion product.

\section{References}

1 Terasaki PI, Park MS, Bernoco D, Opelz G, Mickey MR. Overview of the 1980 International Histocompatibility Workshop. In: Terasaki PI, ed. Histocompatibility testing 1980. Los Angeles: UCLA Tissue Typing Laboratory, 1980: 1-17.

2 Duquesnoy RJ, Marrari M, Annen K. Identification of an HLA-DR-associated system of B-cell alloantigens. Transplant Proc 1979; 11: 1757-60.

3 Duquesnoy RJ, Marrari M, Annen K. Association of the B-cell alloantigen MB1 with HLA-DRw2. Transplant Proc 1980; 12: 138-40.

4 Reinertsen JL, Klippel JH, Johnson AH, Steinberg AD, Decker JL, Mann DL. B-lymphocyte alloantigens associated with systemic lupus erythematosus. $N$ Engl J Med 1978; 299: 515-8. 
5 Moutsopoulos HM, Mann DL, Johnson AH, Chused TM. Genetic differences between primary and secondary sicca syndrome. $N$ Engl J Med 1979; 301: 761-3.

6 Betuel H, Gebuhrer L, Descos L, Bertrand DJ, Freycon F, Lepetit JC. Coeliac disease and its association with HLA markers. In: Terasaki PI, ed. Histocompatibility testing 1980. Los Angeles: UCLA Tissue Typing Laboratory, 1980: 668-72.

7 Longo A, Ferrara GB. Human B-cell. Separation and typing. In: Terasaki PI, ed. Histocompatibility testing 1980. Los Angeles: UCLA Tissue Typing Laboratory, 1980: 283-4.

8 Terasaki PI, Bernoco D, Park MS, Ozturk G, Iwaki Y. Microdroplet testing for HLA-A,B,C, and DR antigens. Am J Clin Pathol 1978; 69: 103-20.

9 Svejgaard A, Jersild C, Staub Nielsen L, Bodmer WF. HL-A antigens and disease. Statistical and genetical considerations. Tissue Antigens 1974; 4: 95-105.

10 Bengtsson BO, Thomson G. Measuring the strength of associations between HLA antigens and diseases. Tissue Antigens 1981; 18: 356-63.

11 Green A. The epidemiologic approach to studies of association between HLA and disease. II. Estimation of absolute risk, etiologic and preventive fraction. Tissue Antigens 1982; 19: 259-68.

12 Keuning JJ, Pena AS, van Leeuwen A, van Hoff JP, van Rood JJ. HLA-Dw3 associated with coeliac disease. Lancet 1976; 1: 506-8.

13 Ek J, Albrechtsen D, Solheim BG, Thorsby E. Strong association between the HLA-Dw3, related B alloantigen DRw3 and coeliac disease. Scand J Gastroenterol 1978; 13: 229-43.

14 Kagnoff MF, Weiss JB, Brown RJ, Lee T, Schanfield MS. Immunoglobulin allotype markers in glutensensitive enteropathy. Lancet 1983; 1: 952-3.

15 McKenna R, Stevens FM, Bourke M, McNicholl B, Albert ED, McCarthy CF. B-cell alloantigens associated with coeliac disease. In: McConnell RB, ed. Genetics of coeliac disease. Lancaster: MTP Press, 1981: 153-8.

16 Pena AS, Biemond I, Rosekrans PCM, van Leeuwen A, Schreuder I, van Rood JJ. DR locus controlled B-cell alloantigens in coeliac disease in the Netherlands. In: McConnell RB, ed. Genetics of coeliac disease. Lancaster: MTP Press, 1981: 161-71.

17 Albert ED, Harms K, Bertele $\mathrm{R}$ et al. B-cell allo- antigens in coeliac disease. In: McNicholl B, McCarthy $\mathrm{CF}$, Fottrell PF, eds. Perspectives in coeliac disease. Lancaster: MTP Press, 1978: 123-8.

18 Betuel H. Gebuhrer L, Descos L, Percebois $H$. Minaire Y, Bertrand J. Adult coeliac disease associated with HLA-DRw3 and DRw7. Tissue Antigens 1980; 15: 231-8.

19 De Marchi M, Borelli I, Olivetti E et al. Two HLA-D and DR alleles are associated with coeliac disease. Tissue Antigens 1979; 14: 306-16.

20 Polanco I, Biemond I, van Leeuwen A et al. Glutensensitive enteropathy in Spain: genetic and environmental factors. In: McConnell RB, ed. Genetics of coeliac disease. Lancaster: MTP Press, 1981: 211-31.

21 Brautbar C, Fraier S, Ashkenazi A et al. Histocompatibility determinants in Israeli Jewish patients with coeliac disease: population and family study. Tissue Antigens 1981; 17: 313-22.

22 Ellis A, Taylor CJ, Dillon-Rommy M, Woodrow JC, McConnell RB. HLA-DR typing in coeliac disease: evidence for genetic heterogeneity. $B r \operatorname{Med} J 1984$; 2: 1571-3.

23 Bodmer J, Bodmer W. Histocompatibility 1984. Immunol Today 1984; 5: 251-4.

24 Duquesnoy RJ. Immunogenetic aspects of the relationship between HLA-DR and the MB and MT systems. Transplant Proc 1981; 13: 1804-7.

25 Volkman DJ, Mann DL, Fauci AS. Association between Takayasu's arteritis and a B-cell alloantigen in North Americans. $N$ Engl J Med 1982; 306: 464-5.

26 Tosi R, Vismara D, Tanigaki N et al. Evidence that coeliac disease is primarily associated with a DC locus allelic specificity. Clin Immunol Immunopathol 1983; 28: 395-404.

27 Duquesnoy R, Marrari A, Vieira J. Definition of MB and MT antigens by 8th International Histocompatibility Workshop B-cell alloantiserum clusters. In: Terasaki PI, ed. Histocompatibility testing 1980. Los Angeles: UCLA Tissue Typing Laboratory, 1980: 861-3.

28 De Marchi M, Carbonara A, Ansaldi N et al. HLADR3 in coeliac disease: immunogenetic and clinical aspects. Gut 1983; 24: 706-13.

29 Pena AS, Mann DL, Hague NE et al. Genetic basis of gluten-sensitive enteropathy. Gastroenterology 1978; 75: $230-5$. 